\title{
OPTIMUM SAMPLING DENSITY FOR THE PREDICTION OF ACID MINE DRAINAGE IN AN UNDERGROUND SULPHIDE MINE
}

\author{
Kostas Modis ${ }^{1}$ and Kostas Komnitsas ${ }^{2}$ \\ ${ }^{1}$ School of Mining and Metallurgical Engineering, National Technical University of Athens, 15773 Zografos, \\ Greece \\ ${ }^{2}$ Department Mineral Resources Engineering, Technical University Crete, 73100 Chania, Greece
}

\begin{abstract}
According to previously established theoretical analysis and under certain conditions, a critical sampling grid can be determined for an earth-related space-distributed natural variable. Sampling above this critical limit adds little to the mapping results. The objective of this paper is the application of the above theory to the Stratonion mixed sulphide mine area in Greece, where Hellenic Chemical Products and Fertilisers Company had conducted a sampling campaign to estimate ore reserves and net neutralization potential of the rock formations. Acid mine drainage was correlated to net neutralization potential. The structural analysis of NNP values generated a variogram model, from which the critical sampling grid was identified. The conclusion drawn is that in some parts of the deposit the sampling grid is denser than required. Finally, an optimal sampling grid is proposed in order to gain the maximum information at the lowest cost.
\end{abstract}

\section{Introduction}

Acid Mine Drainage (AMD) is the result of a complex series of chemical reactions; it is generated among others in active or abandoned mixed sulphide mines, is characterized by low $\mathrm{pH}$ and high concentrations of sulphates and dissolved heavy metal ions and impacts severely surface and groundwater (Kontopoulos et al., 1995). Pyrite $\left(\mathrm{FeS}_{2}\right)$ is the main mineral responsible for acid generation; its overall oxidation reaction is expressed as follows:

$$
2 \mathrm{FeS}_{2}(\mathrm{~s})+7 \mathrm{O}_{2}(\mathrm{aq})+2 \mathrm{H}_{2} \mathrm{O} \rightarrow 2 \mathrm{Fe}^{2+}(\mathrm{aq})+4 \mathrm{H}^{+}(\mathrm{aq})+4 \mathrm{SO}_{4}{ }^{2-} \text { (aq) }
$$

The rate of this reaction is accelerated by several orders of magnitude through the action of Thiobacillus ferooxidans, according to reaction (2):

$$
4 \mathrm{Fe}^{2+}+\mathrm{O}_{2}(\mathrm{aq})+4 \mathrm{H}^{+} \rightarrow 4 \mathrm{Fe}^{3+}+2 \mathrm{H}_{2} \mathrm{O}
$$

$\mathrm{Fe}^{3+}$ produced from reaction (2) oxidizes $\mathrm{FeS}_{2}$ by the indirect reaction (3). The produced $\mathrm{Fe}^{2+}$ ions are again oxidized to $\mathrm{Fe}^{3+}$, according to reaction (2), and participate again in the oxidation of additional quantities of pyrite (autocatalysis).

$$
\mathrm{FeS}_{2}(\mathrm{~s})+14 \mathrm{Fe}^{3+}+8 \mathrm{H}_{2} \mathrm{O} \rightarrow 15 \mathrm{Fe}^{2+}+2 \mathrm{SO}_{4}{ }^{2-}+16 \mathrm{H}^{+}(\mathrm{aq})
$$

The prediction of the acid generation potential of geological formations in surface and underground mines enables the implementation of an environmentally sound exploitation strategy and a closure plan (Adam et al., 1997; Komnitsas et al., 1998). This is implemented by a number of static and kinetic studies; it has to be taken into account that in most cases a combination of experimental studies is required due to the mineralogical complexity of the formations considered. Acid-base accounting (ABA) is a widely accepted and applied static test that determines the balance between acid generating and acid consuming phases in a geological formation. It involves estimation of (a) the acid potential (AP) by considering oxidation of the total sulphur, (b) the neutralisation potential (NP) and (c) the net neutralisation potential (NNP) by subtracting NP from AP. The values of $\mathrm{AP}, \mathrm{NP}$ and NNP are expressed in $\mathrm{kg} \mathrm{CaCO}_{3} / \mathrm{t}$ material. The accuracy of this test is sometimes criticised, since sulphur is present in a number of forms that are not amenable to oxidation. On the other hand, if a big number of samples is under examination and the mineralogy of the formation varies widely, assumptions are taken into account to predict the overall acid generation potential. Modelling and geostatistical techniques can be also used to provide a reliable prediction of this potential (Modis et al., 1998; Komnitsas and Modis, 2006; Modis and Papaodysseus, 2006; Modis et al., 2007).

While highly sophisticated in cases, geostatistical and other estimators are often affected by the quality of the sampling campaign. An important question that should be answered is how representative of the formations the samples are, despite the estimation procedure. Apart from core recovery and accuracy of chemical analyses that can be improved using appropriate techniques, the size of the sampling grid is the main parameter that affects the accuracy of the estimation. The usual practice for determining an optimum grid size is to employ the estimation variance as a criterion of efficiency. 
Kassandra is situated in NE Chalkidiki, Greece, and has been the largest mixed sulphide mining site of the country. It comprises the Stratonion mines, namely Mavres Petres and Madem Lakkos, as well as the Olympias mine, $22 \mathrm{~km} \mathrm{~N}$ of Stratonion. The ore in the Stratonion mines was mined underground by the cut-and-fill method. Earlier, sub-level caving was employed, resulting thus in increased volumes of acid generation.

The geological structure of the area includes a) metamorphic rocks: amphibolites, gneisses, mica schists, hornblende schists and marbles, b) plutonic-Intrusive rocks: foliated granite, granodiorite, lamprophire, aplite, and pegmatite, and c) aplitic rocks connected with the granodiorite that intrude the surrounding metamorphic formation (Nikolaou and Kokonis, 1980).

Mavres Petres orebody is a hydrothermal to mesothermal complex sulphide deposit situated in a relatively small thickness marble, or at the contact between the marble and the surrounding schists or gneisses. Madem Lakkos orebody is also a hydrothermal complex sulphide deposit, situated mainly at the upper contact of a lenticular body of marble of considerable thickness with the overlying gneiss.

In the present paper, using a mathematical approach based on information theory, the estimation of the optimum sampling density for the prediction of AMD at the Madem Lakkos and Mavres Petres mines is presented. Up to date, the usual practice for determining an optimum grid size was to employ the estimation variance as a criterion of efficiency (David, 1976; Dowd and Milton, 1987): One experiments with various grid setups and plots the average estimation variance as a function of sampling density. The optimal grid size is the threshold for which further decrease offers no estimation variance improvement. The contribution of this work is that, avoiding this subjective and awkward process, it calculates the theoretical optimum sampling grid size, with a minimum mean square error, that enables the accurate representation of the existing formations. Therefore this work is complementary to the methodology followed up to date.

\section{Sampling and NNP estimation}

The estimation of the NNP model was based on a set of 171 exploratory drill holes covering the Madem Lakkos and Mavres Petres area (Modis et al., 1998). The only available numerical data from the loggings were the chemical analyses of some mineralized drill-hole samples; it is known that for the development of a reliable 3D mathematical model it is necessary to calculate all NNP values of the rock formations. Since it was not possible to calculate these values for all available core samples, it was decided to deduce mean values for the different formations and assign them to the existing drillhole loggings (Modis et al., 1998).

The structural analysis of the NNP spatial distribution according to geostatistics includes the estimation of the NNP variogram function as a measure of the variability in different directions in space. The mean experimental variograms were calculated in each of the five spatial directions as shown in Figure 1. It is clear that no significant difference is seen in any specific direction, so isotropy can be reasonably assumed. The fitted function $\gamma(\mathrm{r})$ is an isotropic spherical model with sill $\mathrm{C}_{\mathrm{o}}=40000\left(\mathrm{~kg} \mathrm{CaCO}\right.$ equiv/ $\mathrm{t}$ sample) ${ }^{2}$ and range of influence a=90 m (Modis et al., 1998).

\section{Related Notions and Theorems from the Sampling Theory}

Originally developed for deterministic electrical signals, information theory deals with the estimation problem set in the previous section, when a signal has to be reconstructed from its samples. Reconstruction involves filtering of the sampled signal by an interpolation filter and if the conditions of the sampling theorem are satisfied (Papoulis and Pillai, 2002), then the original signal is exactly reproduced.

In a bandlimited function, the spectrum vanishes above a certain frequency limit. The spectrum of an arbitrary sampled bandlimited function is a scaled, periodic replication of the spectrum of the original function (Pratt, 1991). If there is no spectrum overlapping (the sampling frequency is greater than a critical value called the Nyquist rate), then the original function can be reconstructed from its samples by linear filtering. The transfer function of the filter must be such that when applied to the samples sequence spectrum, the spectrum of the resulting signal is identical to the original. In other words, the filter has to clear the spectrum from all replicas and keep only one. The only appropriate function for this operation is the square pulse and so this is the transfer function of the ideal interpolation filter.

But what is a product in the frequency domain is a convolution in the time or space domain. The sinc function,

$$
\operatorname{sinc}(x)= \begin{cases}1, & x=0 \\ \frac{\sin (\pi x)}{\pi x}, & x \neq 0\end{cases}
$$

is the continuous inverse Fourier transform of the rectangular pulse $\Pi(x)$ of width $2 \pi$ and height 1 : 


$$
F[\Pi(x)]=\frac{1}{2 \pi} \int_{-\pi}^{\pi} e^{i \omega x} d x=\operatorname{sinc}(x) .
$$

Since the Fourier transform of the sinc function is the square pulse function, the convolution of the sinc function with the samples will produce the original function as shown in Figure 2a. Thus, the ideal interpolation filter is the sinc function. The critical Nyquist frequency for band limited signals is two times higher than the signal bandwidth.

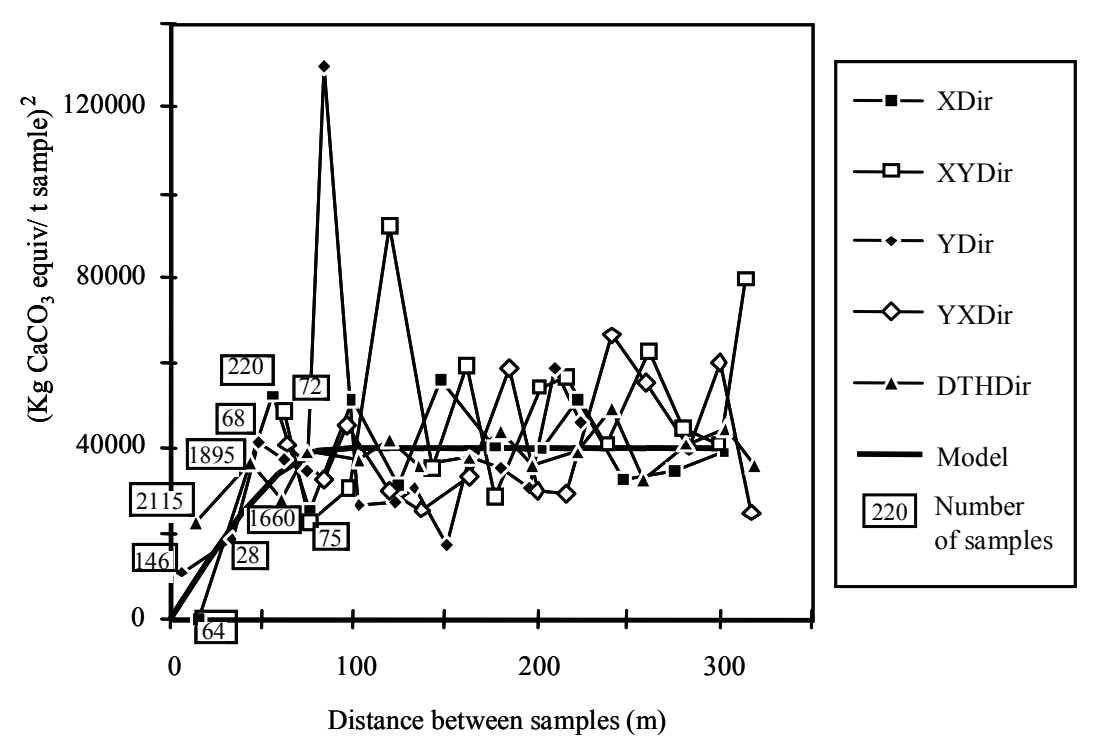

Figure 1. Experimental mean variograms and fitted isotropic model.

Besides the square pulse function, other easier to realize in practice functions can be used as approximate transfer functions to interpolate the sampled function in one or two dimensions. All deterministic interpolation methods can be defined this way (Fig. 2b and 2c) by selection of appropriate transfer functions. When the sampling rate is lower than the Nyquist limit, then overlapping of the infinite copies of the initial spectrum is seen and, as a consequence, all aforementioned approximations are intrinsically problematic. Therefore, causal approaches must be abandoned and stochastic approximations must be considered instead (Modis et al., 2007).

It is well known that in earth related sciences, natural variables under investigation are usually modelled as random fields. In that case, the most common random field models, described by a covariance function with an influence range 'a', are approximately band limited (as for example the "spherical scheme" in Figure 3 with Nyquist interval (lag) $\Delta s=\mathrm{a} / 2$ (Modis and Papaodysseus, 2006).

In other words, if the structural analysis of the ore body reveals an underlying structure with a certain range of influence, then the optimum exploratory grid size is determined to half the value of this range.

\section{Sampling geometry and efficiency}

The studied deposits have been surveyed by a drilling campaign, which includes 171 drill holes. The location of each drill hole is presented in Figure 4. It can be easily seen from this figure that not only the drilling did not follow any grid configuration but also the distance between the drill holes varies widely. The closest distance between two successive drill holes was $20 \mathrm{~m}$ while the longest was $250 \mathrm{~m}$. The average distance was about 150 $\mathrm{m}$. Higher concentration of drill holes is observed in the south-central (Madem Lakkos mine) and north-west (Mavres Petres mine) parts. The distances between drillholes in these areas varies between 20 and $120 \mathrm{~m}$ while in the other parts distance varies between 100 and $250 \mathrm{~m}$. Thus, a separate distance distribution with different averages for each part can be identified.

It is also seen in Figure 1, that the structural analysis of NNP values reveals a range of influence up to $90 \mathrm{~m}$. Using the above mentioned formula to estimate the optimum sampling grid, a value of $45 \mathrm{~m}$ is obtained (Modis and Papaodysseus, 2006). 


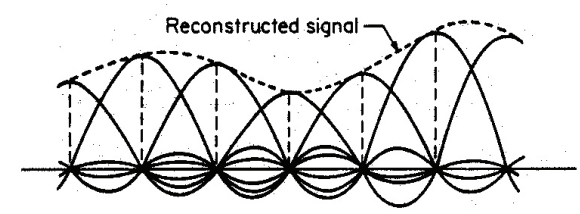

(a) Sinc function

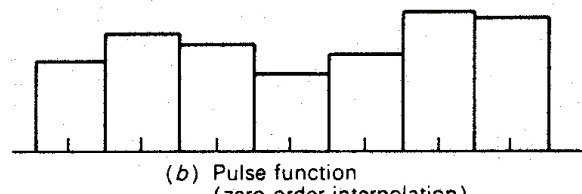

(zero order interpolation)

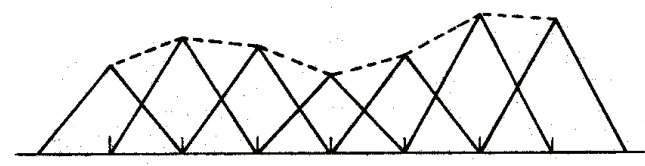

(c) Ramp function

(first order interpolation)

Figure 2. Signal reconstruction.

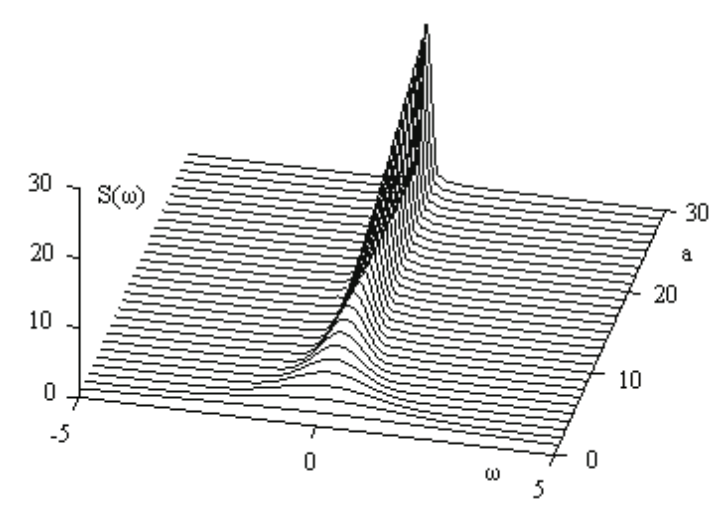

Figure 3. Fourier transform of the spherical correlation model as a function of range of influence ' $a$ '.

From the above analysis it is easily seen that some parts of the wider mining area under study are over-sampled since drillhole distances can be as short as $20 \mathrm{~m}$ which is shorter than the recommended distance of $45 \mathrm{~m}$. The rest of the area is under-sampled since no drill holes are as close as the optimum distance. Thus, the drill holes are distributed unevenly indicating over-sampling in some parts and under-sampling in others.

\section{Conclusions}

The main conclusions derived from this study are the following:

- The variogram model generated by structural analysis of NNP spatial distribution in the mining area under study enables the establishment of a critical sampling grid; in some parts of the ore body the sampling grid is denser than required.

- If the density of the sampling grid is close to the critical value, the calculation of the NNP numerical model can be implemented by using simpler interpolation algorithms, such as inverse distance square having equal accuracy to geostatistics.

- In general, the design of the drilling campaign can be considered as an optimization problem. The selection of the appropriate drillhole network in relation to the grid size can maximize the information regarding the distribution of NNP values required for estimation and prevention of AMD; it can also contribute to considerable savings in money and time.

- In order to increase the probability of an accurate estimation of the acid generation potential of a geological formation using NNP or other values deriving from established static or kinetic tests, the optimum sampling density should be considered by taking into account topography and geology of the site (e.g. 
faults, lenses of different materials, permeability of the overlying formations etc). In addition, only the sulphur content that is amenable to oxidation should be used in the respective calculations.

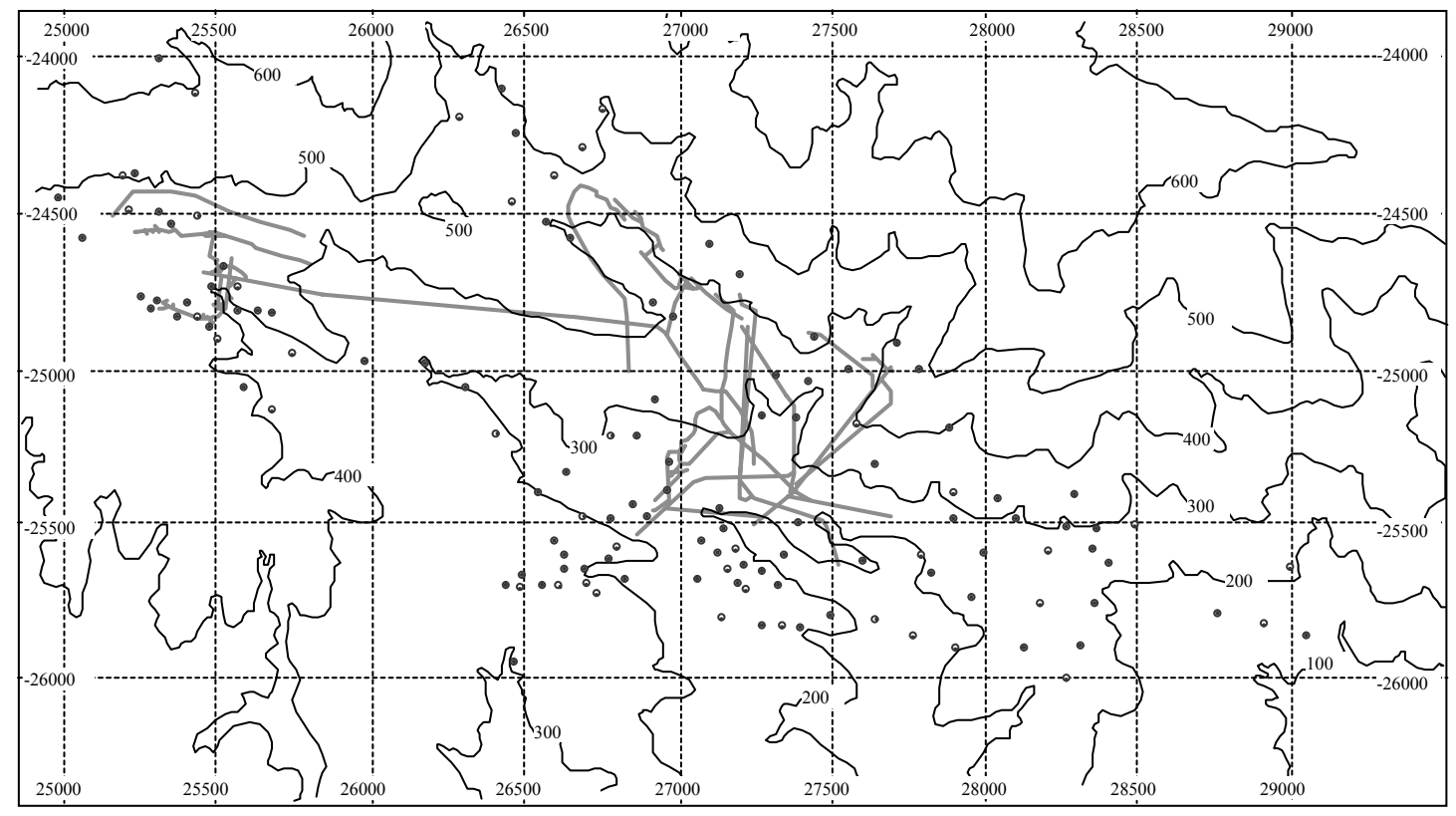

Figure 4. Drill hole locations and underground works in the Stratonion mining area.

\section{Acknowledgements}

The authors would like to acknowledge the financial contribution of the Greek General Secretariat of Research and Technology in the framework of the bilateral Sino-Greek project entitled "Integrated rehabilitation options in contaminated areas and waste disposal sites using novel methodologies".

\section{References}

Adam K., Kourtis A., Gazea B., Kontopoulos A. (1997). Evaluation of static tests used to predict the potential for acid drainage generation at sulphide mines. Transactions IMM Section A 106, A1-A8.

David, M. (1976). What Happens If? - Some Remarks on Useful Geostatistical Concepts in the Design of Sampling Patterns. Proceedings: Symposium on Sampling Practices in the Minerals Industry, Australasian Institute of Mining and Metallurgy, 1- 15.

Dowd P.A., Milton D.W. (1987). Geostatistical Estimation of a Section of the Perseverance Nickel Deposit. In Geostatistical Case Studies, G. Matheron and M. Armstrong (eds), Reidel, , 39- 67.

Komnitsas K., Kontopoulos A., Lazar I., Cambridge M. (1998). Risk assessment and proposed remedial actions in coastal tailings disposal sites in Romania. Minerals Engineering 11, 1179-1190.

Komnitsas K., Modis K. (2006). Soil risk assessment of As and Zn contamination in a coal mining region using geostatistics. Science of the Total Environment 371, 190-196.

Kontopoulos A., Komnitsas K., Xenidis A., Papassiopi N. (1995). Environmental characterisation of the sulphidic tailings in Lavrion. Minerals Engineering 8, 1209-1219.

Modis K., Adam K., Panagopoulos K., Kontopoulos A. (1998). Development and validation of a geostatistical model for prediction of acid mine drainage in underground sulphide mines. Trans IMM Section A 107, 102-107.

Modis K., Papaodysseus K. (2006). Theoretical estimation of the critical sampling size for homogeneous orebodies with small nugget effect. Mathematical Geology 38(4), 489-501.

Modis K., Papantonopoulos G., Komnitsas K., Papaodysseus K. (2007). Mapping optimization based on sampling size in earth related and environmental phenomena. Stochastic Environmental Research Risk Assessment, Published Online First: DOI 10.1007/s00477-006-0096-8.

Nikolaou M., Kokonis I. (1980). Geology and development of the Olympias mine, eastern Chalkidiki, Macedonia, Greece. In Complex sulphides ores (ed. M. J. Jones), Institute Mining Metallurgy, London, 260-270. Papoulis A., Pillai U. (2002). Probability, Random Variables and Stochastic Processes. McGraw Hill, NY, 852p. Pratt W.K. (1991). Digital image processing. Wiley-Interscience, New York, 698p. 